\title{
Los Romances imperiales de Pedro de Sayago: pistas e hipótesis de un texto desaparecido
}

\author{
Andrés Rosselló OLIVER \\ (Investigador independiente)
}

Resumen

Pedro de Sayago escribió los Romances imperiales en pleno fervor imperial, y fueron impresos en Sevilla por Alonso de Coca el año 1565. A pesar de que a día de hoy no conocemos de la existencia de ningún testimonio de época de esta obra, los Romances imperiales gozaron de cierta relevancia, según muestran sus múltiples menciones. El contenido del romancero nos es desconocido, así como el paradero actual de alguno de sus ejemplares, pero disponemos de datos suficientes como para que en las páginas que siguen podamos trazar un recorrido por la historia bibliográfica de esta obra y plantear ciertas hipótesis que puedan servir de punto de partida para posteriores búsquedas y estudios.

Palabras clave: Pedro de Sayago; Romances imperiales; Alonso de Coca; Pedro Mexía; Historia ymperial y cesárea; Hubert Goltzius; Los vivos retratos de todos los emperadores; Carlos V.

\section{The Romances imperiales of Pedro de Sayago: Clues and Hypothesis about a Lost Text}

Abstract

Pedro de Sayago wrote his Romances imperials in the grip of imperial fervour; they were printed in Seville by Alonso de Coca in 1565. As numerous references to them suggest, the Romances imperiales were important, even though we have no contemporary evidence about them. The text of this collection of ballads has not come down to us, nor do we know the whereabouts of any copy. However, as the following pages show, we do have

Titivillus, ISSN 2387-0915, ISSN-e 2603-9966, 4 (2018), pp. 27-37 $\quad$ Recibido: 2017-10-31. Aceptado: 2017-12-02 
enough information to trace the bibliographical history of this literary work. We can also propose some hypotheses that provide a starting point for future research and studies.

Keywords: Pedro de Sayago; Romances imperiales; Alonso de Coca; Pedro Mexía; Historia ymperial y cesárea; Hubert Goltzius; Los vivos retratos de todos los emperadores; Charles V.

\section{Noticias biográficas de Pedro de Sayago}

Pedro de Sayago fue uno de los muchos escritores que proliferaron a mediados del siglo XVI y que tuvieron la mala fortuna de convivir con algunas de las más brillantes plumas que nos han dejado nuestras letras: Fernando de Herrera, Fray Luis de León, San Juan de la Cruz, Santa Teresa de Ávila, etc. La carencia de cualquier fuente primaria en la que aparezca el nombre de Pedro de Sayago, y el silencio al que le han sometido las fuentes secundarias (unas veces por puro desconocimiento y otras por un injustificado desprecio, como explicaremos más adelante) dificultan la tarea de quien aspira a adentrarse en la compleja maraña de desafortunadas coincidencias que ha desembocado en el olvido de este poeta que escribió, por lo que sabemos, en los años centrales del siglo XVI. Las dos obras que podemos atribuirle, cada una de ellas con su particular y curiosísima historia, son: la Batalla de la Muerte, la cual se dio al Emperador D. Carlos y a otros XIV Grandes que con él fueron, el año de $1558^{1}$ y los Romances imperiales de todos los Emperadores Romanos desde Julio César hasta el Emperador Maximiliano (Alonso de Coca, Sevilla, 1565). Ninguna de las dos se nos ha conservado en edición de época. ${ }^{2}$

La temática imperial de ambas obras sugiere que su autor pretendía congraciarse con los poderosos. Los vínculos de Sayago con la alta aristocracia de su tiempo vienen reforzados por la información que proporciona el erudito sevillano Nicolás Antonio (1617-1684): «scripsit ad Alphonsum Pereæium de

\footnotetext{
${ }^{1}$ Esta obra, interesante y desaparecido testimonio manuscrito de las Danzas de la Muerte, reelabora la tradición macabra con el influjo manriqueño, y convierte a Carlos $\mathrm{V}$ en el centro de un grupo de poderosos ante los que se aparece la Muerte para anunciarles su inminente fallecimiento.

${ }^{2}$ Existe edición decimonónica de la Batalla de la Muerte en Marcelo Macías y García, «Batalla de la Muerte, la cual se dio al Emperador D. Carlos y a otros XIV Grandes que con él fueron el año de 1558», en Marcelo MACÍAS Y GARCíA, Poetas religiosos inéditos del siglo XVI sacados a luz, con noticias y aclaraciones, La Coruña, Tipografía de la Papelería de Ferrer, 1890, pp. 151-187. No obstante, la edición y el estudio realizados en mi Trabajo de Fin de Máster verán la luz próximamente.
}

Titivillus, ISSN 2387-0915, ISSN-e 2603-9966, 4 (2018), pp. 27-37 
Guzman, Medina Sidonice ducem». ${ }^{3}$ El vínculo entre Pedro de Sayago y Alfonso Pérez de Guzmán y Sotomayor (1550-1615), Duque de Medina Sidonia, no ha podido ser confirmado por documentos de época, pero otro indicio importante de dicha relación se encuentra en la Batalla de la Muerte, en la que el abuelo de Alfonso Pérez de Guzmán, Juan Alonso Pérez de Guzmán y Pérez de Guzmán (1502-1558), tiene un papel muy relevante en la obra, superado sólo por el del Emperador Carlos V. La Batalla de la Muerte proporciona algunos detalles que apuntarían a que, a la altura de 1558, Sayago ya estaba al servicio de la casa ducal: en el poema se nos proporcionan detalles como la participación del Duque en las Cortes de Toledo de 1538 o en la comitiva de recepción de la Princesa María Manuela de Portugal el año 1543, de la que cabría la posibilidad de que Sayago fuera el «anónimo cronista que se vio obligado a enumerar la «Relación de la gente que el duque de Medina llevó de su casa al recebimiento de la Princesaum». ${ }^{4}$

Para terminar de trazar el posible perfil biográfico de Pedro de Sayago, podemos suponerle unos extensos conocimientos en leyes, a tenor del rico vocabulario jurídico de que hace uso en la Batalla de la Muerte: «es ya dada la sentencia» (v. 250), «la Justicia Mayor» (v. 343), «es la hora llegada/ que vengáis a residencia» (vv. 654-655), «el juez es, cierto, tan largo,/ que paga ciento por uno/ a quien le da buen descargo» (vv. 663-665), «su citatoria» (v. 686), «no podéis apelar/ después de dada sentencia» (vv. 939-940), «letrados y oradores» (v. 953) o «alcaldes mayores» (v. 955).

\section{Los Romances imperiales: datos editoriales y comerciales}

De los Romances imperiales conservamos la Provisión Real que se concedió en Madrid, el 30 de noviembre de 1564, a Pedro de Sayago con la licencia para su impresión, tal y como consta en el Registro General del Sello del Archivo de Simancas. ${ }^{5} \mathrm{Al}$ año siguiente, en 1565, fueron impresos en Sevilla, en casa de

\footnotetext{
${ }^{3}$ Nicolás AnTONIO, Bibliotheca Hispana Nova sive hispanorum qui ab anno md. ad mdclxxxiv. floruere notitia. auctore D. Nicolao Antonio Hispalense I.C. Ordinis S. Iacobi equite, patriae Ecclefiae canonico, Regiorum negotiorum in Urbe \& Roman curia procuratore generali, confiliario Regio. Nunc primun prodit recognita emendata aucta ab ipso auctore, Madrid, Imprenta de Joaquín Ibarra, 1788, II, pág. 237.

4 Mercedes Fernández VALLADARES, «Historia y política en las relaciones góticas de la Colección Medinaceli (Descripciones: segunda parte)», en María Cruz GARCÍA DE ENTERRía et al. (eds.), Las relaciones de sucesos en España (1500-1750). Actas del Primer Coloquio Internacional (Alcalá de Henares, 8, 9 y 10 de junio de 1995), Alcalá-París, Publications de La Sorbonne- Servicio de Publicaciones de la UAH, 1996, pp. 133-155. Agradezco a la profesora Mercedes Fernández Valladares que me sugiriera la posible identificación de Pedro de Sayago con este cronista, así como sus sabias recomendaciones a lo largo de la elaboración del trabajo que desembocó en la publicación de este artículo.

5 Rafael M. PÉREz GARCíA, La imprenta y la literatura espiritual castellana en la España del Renacimiento. 1470-1560, Gijón, Trea, 2006, p. 411. Aparece con el número 98 de las 99 provisiones reales de licencia de impresión que se suministran en este libro.
} 
Alonso de Coca. Resulta curioso que, dentro de los trabajos de este impresor sevillano, los Romances imperiales constituyan la única obra que no pertenece al género de las relaciones de sucesos, así como por su formato de pequeñas dimensiones (in octavo, frente a los pliego sueltos del resto de noticieros que imprimió, al menos, entre 1559 y 1568, que fluctúan entre el formato folio y el cuarto).

Sólo podemos dar por segura esta edición de 1565, de la que no se conservan ejemplares conocidos, aunque García Oro Marín y Portela Silva dan noticia de la existencia de una Provisión Real, fechada en 18 de abril de 1573 y otorgada a un librero de Madrid, Gaspar de Ortega, con la licencia para «la impresión de las obras de Garcilaso de la Vega y Los Romances de los Emperadores». ${ }^{6}$ A este respecto, añade Laura Puerto que, «aceptada la identificación [de Los Romances de los Emperadores] con Sayago, no conocemos en la actualidad ninguna edición, si es que ésta llegó a producirse». ${ }^{7}$ En efecto, no hemos podido hallar edición alguna de Garcilaso costeada por Ortega; podemos dudar incluso de que llegara a realizarse, como cabe la posibilidad de que sucediera con esta segunda edición de los Romances imperiales de Sayago.

No obstante, podríamos sugerir la existencia de una edición posterior a la segura, la de 1565, puesto que en 1600 el librero Luis de Padilla envió a San Juan de Ulúa (México), entre otros muchos libros, un ejemplar de los Romances imperiales, que en el registro de viajes aparece como «Romançero de Pedro Sayago» ${ }^{8}$. Los años que median entre ambas fechas sugieren que el volumen que consta en su inventario debió de pertenecer a una edición no documentada realizada con posterioridad a 1565, o pudo tratarse de un ejemplar viejo que probó mejor suerte en el mercado que abría el Nuevo Mundo.

A pesar de que en el Diccionario bibliográfico de pliegos sueltos poéticos de Rodríguez-Moñino no se incluyen los Romances imperiales, en el Nuevo Diccionario bibliográfico de pliegos sueltos poéticos se incorpora una Nota que dice lo siguiente: «La falta de datos sobre la extensión de la obra no permite asegurar que se trata de un pliego suelto de 20 hojas». ${ }^{9}$ Rodríguez-Moñino, al documentar los

\footnotetext{
' José García Oro Marín y María José Portela Silva, La Monarquía y los libros en el Siglo de Oro, Alcalá de Henares, Centro Internacional de Estudios Históricos «Cisneros», Universidad de Alcalá, 1999, p. 350.

7 Arthur L.-F. ASKINS y Víctor INFANTES, Suplemento al Nuevo Diccionario bibliográfico de pliegos sueltos poéticos (siglo XVI) de Antonio Rodríguez-Moñino, ed. Laura Puerto Moro, Vigo, Editorial Academia del Hispanismo, 2014, núm. 545.6.

8 En Irving A. LeONARD, Los libros de conquistador, México D.F, Fondo de Cultura Económica, 2000 (original inglés de 1949; primera edición del Fondo de Cultura Económica de 1953), p. 486.

9 Antonio Rodríguez-Moñino, Nuevo Diccionario Bibliográfico de Pliegos Sueltos Poéticos (Siglo XVI), ed. corregida y actualizada por Arthur L.-F. Askins y Víctor Infantes, Madrid, Editorial Castalia, Editora Regional de Extremadura, 1997, p. 479.
}

Titivillus, ISSN 2387-0915, ISSN-e 2603-9966, 4 (2018), pp. 27-37 
Romances imperiales en su Manual bibliográfico de Cancioneros y Romanceros ${ }^{10}$ y no en el Diccionario bibliográfico, debió de considerar que no estaba ante un pliego suelto, sino ante un libro de mayor volumen. Por el inventario del librero granadino Martín de Salvatierra, ${ }^{11}$ sabemos que en 1571 había por lo menos seis ejemplares de los Romances imperiales, cada uno de ellos valorado en 25 maravedíes y anotados bajo la rúbrica de «Libros enquadernado pargamino». Tanto el precio de cada ejemplar como el material de su encuadernación refuerzan la suposición de que los Romances imperiales no fueron un pliego suelto, sino un volumen compuesto por un número no especificado (seguramente elevado) de composiciones poéticas.

En cualquier caso, más allá de estas suposiciones, los datos de que disponemos sólo dan fe de una edición: la que se realizó el año 1565 en Sevilla, in octavo y a cargo del impresor Alonso de Coca. En breve saldrá a la luz La imprenta en Sevilla (1501-1600), obra póstuma de Arcadio Castillejo Benavente, tipobibliógrafo y exdirector de la sección de Fondo antiguo de la Biblioteca Universitaria de Sevilla, en la que el lector podrá localizar todas las referencias existentes a los Romances imperiales en catálogos y diccionarios bibliográficos, así como los artículos que los mencionan. ${ }^{12}$

\section{Consideraciones estilísticas}

El otro punto en el que debemos detenernos, y que nos servirá para terminar de presentar los Romances imperiales, es la última parte de la entrada bibliográfica de la Bibliotheca Hispana Nova: «Ab hujus cognomine, ut suspicari datur, rustici oris hominem \& stilum Sayagues dicimus». ${ }^{13}$ Expresa de este modo Nicolás Antonio su sospecha de que el estilo de los Romances imperiales reproduce el habla rústica que conocemos como 'sayagués', y sugiere que de allí le viene el apellido al poeta. Pese a la erudición que demuestra Nicolás Antonio a lo largo de su opera magna, esta falsa etimología cae por su propio peso: sin tener por qué buscar consecuencias estilísticas, Pedro de Sayago podría apellidarse así a modo de simple indicación de su procedencia (como es el caso de Antonio de Nebrija) o por ser la tierra de origen de sus antepasados. Además, el apellido

\footnotetext{
10 Antonio RodrígueZ-MoÑInO, Manual bibliográfico de Cancioneros y Romanceros. I. Siglo XVI, Madrid, Editorial Castalia, 1973, núm. XXXVIII.

11 Sigo la edición del inventario incluida por María José OsORIO PÉREZ, Amparo MORENO TRUjILlo y Juan María DE LA OBRA SIERRA en Trastiendas de la cultura. Librerías y libreros en la Granada del siglo XVI, Granada, Universidad de Granada, 2001, pp. 212-286. Dicho inventario se realizó, tal y como consta en el documento, el 14 de mayo de 1571, después de nueve días de haber fallecido Martín de Salvatierra y a petición de su viuda, María de Espinosa.

12 Arcadio Castillejo Benavente, La imprenta en Sevilla (1501-1600). [En prensa]. Agradezco a Eduardo Peñalver su amabilidad al proporcionarme esta información, y a Mercedes Fernández Valladares por su mediación.

13 Véase N. Antonio, Nova, II, p. 237.
} 
«Sayago» está documentado en la época sin que pueda atribuirse a todos sus poseedores una vinculación con el habla sayaguesa: en el Diccionario biográfico español aparece, por ejemplo, Diego Sayago (nacido en Bolivia hacia 1585 y muerto con posterioridad a 1652 en Sucre)..$^{14}$

Un indicio más que pone en entredicho el habla y procedencia sayaguesas de nuestro poeta es la pulcritud con la que se expresa en la Batalla de la Muerte, cuyo motivo (el fallecimiento de grandes personalidades del momento) anulaba la posibilidad de abordar el asunto desde la expresión rústica.

Volviendo, por tanto, sobre la información que proporciona Nicolás Antonio en cuanto a la asociación entre el apellido de Sayago y el nombre del dialecto regional zamorano, cabe destacar que ha constituido una fuente a la que han ido los que han elaborado diccionarios bibliográficos desde el siglo XIX y han incorporado a Sayago en ellos. Esto último se observa, por ejemplo, en Brunet: «Ces romances sont écrites d'un style si plat, que le nom de l'auteur est devenu proverb en Espagne pour désigner un langage rude et grossiens..$^{15} \mathrm{En}$ su introducción a la Batalla de la Muerte, Macías y García insiste en la mala calidad de «los Romances imperiales, tan faltos de inspiración, como duros y desaliñados en el lenguaje», ${ }^{16}$ a pesar de que tal juicio pudo ser producto de la opinión de segundo o de la propia entrada de la Bibliotheca Hispana Nova. También Escudero y Perosso se refiere a «lo perverso de su estilo, que quedó en proverbio» ${ }^{17}$.

Como conclusión, Pedro de Sayago, lejos de ser un escritor desconocido por la crítica, aparece mencionado ya en la Bibliotheca Hispana Nova del siglo XVII, y lo largo del XIX los estudiosos magnificaron las palabras de Nicolás Antonio, al que con toda seguridad convirtieron en referente de juicios que, como en este caso, parecen estar basados en un desafortunado equívoco. Estas y otras muchas cuestiones se irán despejando a medida que avancen los estudios y la búsqueda de los Romances imperiales, que en un futuro puede dar sus frutos y culminar con el hallazgo de algún testimonio hoy en día desconocido.

\section{La búsqueda de propietarios, y sus resultados}

Tras la consulta de numerosos catálogos e inventarios, han podido localizarse hasta siete individuos que poseyeron o dijeron poseer en algún

\footnotetext{
14 Real ACADemia de la Historia, Diccionario biográfico español, Madrid, Real Academia de la Historia, 2013, XLVI p. 353.

15 Jacques-Charles BRUNET, Manuel du Libraire et de l'amateur de livres, Bruxelles, Société Belge de Librairie, 1839, IV, p. 162. Al final de la entrada de los Romances imperiales, en la edición segura de Coca de 1565, Brunet añade que este libro es «extrêmement rare».

16 Marcelo MaCíAS Y GARCíA, Poetas religiosos inéditos del siglo XVI, sacados á luz, con noticias y aclaraciones, p. 150.

17 Francisco Escudero y Perosso, Anales bibliográficos de la ciudad de Sevilla desde el establecimiento de la imprenta hasta fines del siglo XVIII, Madrid, Establecimiento tipográfico «Sucesores de Rivadeneyra», 1894, p. 27.
}

Titivillus, ISSN 2387-0915, ISSN-e 2603-9966, 4 (2018), pp. 27-37 
momento algún ejemplar de los Romances imperiales de Pedro de Sayago. Entre sus propietarios se encuentran personalidades de gran renombre dentro del mundo de la bibliofilia y del comercio editorial hispánicos, como se verá a continuación:

1. El librero de Granada Martín de Salvatierra, a cuyo inventario, realizado tras su muerte el año 1571, ya hemos aludido. Resulta fácil inferir que los seis ejemplares que documenta en dicho inventario pertenecen a esa primera edición (y única conocida) de los Romances imperiales (1565) de Pedro de Sayago, aunque los editores modernos del recuento de bienes, en la identificación de autores y obras, no proporcionen el nombre de Pedro de Sayago al referirse a estos Romances imperiales, indudablemente escritos por nuestro poeta.

2. El polifacético autor y estudioso Jerónimo de Chaves (1523-1574). En el inventario de sus bienes aparecen mencionados los Romances imperiales. ${ }^{18}$

3. Don Diego Sarmiento de Acuña, primer Conde de Gondomar (15671626). El año 1598 su hermano, don García, adquirió «de la testamentaría de un canónigo de Toledo varios libros apreciables por su mérito y antigüedad», ${ }^{19}$ entre los que se encontraba el poemario de Sayago. Desconocemos quién era dicho canónigo y cómo y cuándo se hizo con los Romances.

4. El librero sevillano Luis de Padilla, quien en 1600 envió desde Sevilla un cargamento con seis cajas de libros hacia San Juan de Ulúa (México), entre los que se encontraba un ejemplar de los Romances imperiales. Lejos de ser una simple referencia más, que nuestro libro viajara a América da muestra del interés que podía tener para los nuevos colonos o para los que ya se habían asentado en el continente. Se le asigna el valor de un real. Sabemos que el barco en el que viajó este cargamento, el Santísima Trinidad, llegó a su destino, ${ }^{20}$ y allí se le pierde la pista, sin que a día de hoy sepamos qué suerte corrió en el Nuevo Mundo su cargamento, entre el que se encontraban nuestros Romances imperiales.

5. Juan de Aguiar y Acuña, caballero de la orden de Santiago, quien seguía

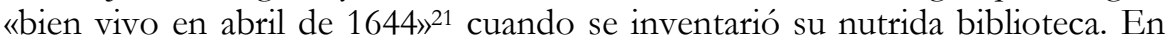

\footnotetext{
${ }^{18}$ La entrada directa a la ficha del libro está accesible en la red, a través del portal Spanish Republic of Letters (SRL): [http://cdigs.uwindsor.ca/srl/node/1399].

19 Pascual de Gayangos, Cinco cartas politico-literarias de D. Sarmiento de Acuña, primer conde de Gondomar, embajador á la córte de Inglaterra. 1613-22, Madrid, Sociedad de Bibliófilos, 1869, p. XIV.

${ }^{20}$ Huguette Chaunu y Pierre Chaunu, Séville et l'Atlantique (1504-1650), Paris, École Pratique des Hautes Études, VIe Section, Centre de Recherches Historiques, 1956, 8 v., p. 94-95.

${ }^{21}$ Trevor J. DADSON, «La publicación y diseminación de obras de entretenimiento en la España del siglo XVII», en Manuel José PEDRAZA GARCía (dir.), Del autor al lector: el comercio y distribución del libro medieval y moderno, Zaragoza, Prensas de la Universidad de Zaragoza, 2017, p. 88.
} 
dicho inventario aparecen registrados hasta dos Romances imperiales, ${ }^{22}$ que sin duda son dos ejemplares del romancero de Pedro de Sayago.

6. El erudito y coleccionista don Vincencio Juan de Lastanosa (16071684), quien recibió los Romances imperiales en abril del año 1647 de manos del «doctor Juan Francisco Andrés, cronista del Reino de Aragón». ${ }^{23}$

7. Don Bartolomé José Gallardo (1776-1852), quien perdió en la noche de San Antonio de 1823, junto a una parte importante de su biblioteca y estudios literarios manuscritos, un ejemplar del Romancero de Pedro de Sayago, acerca del que añade Rodríguez-Moñino al realizar la lista de pérdidas de Gallardo: «Jamás hemos podido ver tan rarísimo libro», ${ }^{24}$ en alusión a que no fue recuperado por el bibliógrafo tras tan importante pérdida.

Además de estos siete poseedores que hemos podido localizar a lo largo del presente trabajo, hay constancia de que el propio Nicolás Böhl de Faber (1770-1836) estuvo interesado en obtener, entre otros muchos libros, los Romances imperiales de Sayago, ${ }^{25}$ aunque José Hidalgo, el que debía proveérselos, no pudo localizar ningún ejemplar, así como de otros muchos escritos que le encargó. ${ }^{26}$ Böhl de Faber, ante el fracaso de Hidalgo, sugirió que tal vez podría dar con algunos de los libros que le había pedido «si pudiera averiguar por dónde se ha desparramado la biblioteca del conde de Aguila [sic], que tenía tesoros de esta clase, manuscritos y impresos». ${ }^{27}$ El hispanista germano se refería al expolio de la biblioteca del III Conde de Águila, Juan Ignacio de Espinosa y Tello de Guzmán, quien en 1808 fue apresado en Sevilla por sus ideas afrancesadas en el marco del levantamiento popular contra José Bonaparte. El Conde de Águila murió asesinado el 8 de mayo de dicho año, y su biblioteca fue saqueada. En ella quizá pudieron haber estado los Romances imperiales, aunque desconocemos si Nicolás Böhl de Faber pensaba que la obra de Sayago en concreto pudiera estar entre los libros de Juan Ignacio de Espinosa.

22 Trevor J. DADSON, «La publicación y diseminación de obras de entretenimiento en la
España el siglo XVII»... p. 91 .
23 Así consta en el inventario recuperado por el Proyecto Lastanosa: [http://www.
lastanosa.com/contenido.php?gama=1\&tipocontenido=127\&tipo=1\&elemento=34].
${ }^{24}$ Antonio RoDRíGUEZ-MoÑINO, Historia de una infamia bibliográfica. La de San Antonio de
1823. Realidady leyenda de lo sucedido con los libros y papeles de don Bartolomé José Gallardo, Madrid,
Editorial Castalia, 1965, p. 194 .
${ }^{25}$ Klaus WAGNER, «Preocupaciones bibliográficas de Juan Nicolás Böhl de Faber (A
propósito de dos cartas desconocidas del literato alemán», en Dicenda. Cuadernos de Filología
Hispánica, 1982, 1, pp. 209-217. Los Romances llevan el número 62 de la segunda carta.
26 El único libro que pudo localizar José Hidalgo de entre los sesenta y tres que solicitó
Nicolás Böhl de Faber fue el Florando de Castilla, lauro de caballeros de Jerónimo Gómez de la
Huerta, en una edición alcalaína de 1588, en formato cuarto e impreso por Juan Gracián.
Lleva el núm. 1009 en Julián MARTIN ABAD, La imprenta en Alcalá de Henares (1502-1600),
Introducción de José Simón Díaz, Madrid, Arco Libros, 1991, 3 v. ${ }^{27}$ Klaus WAgNER, «Preocupaciones bibliográficas de Juan Nicolás Böhl de Faber...», p. 217.

Titivillus, ISSN 2387-0915, ISSN-e 2603-9966, 4 (2018), pp. 27-37 
Sin embargo, la realidad es que los Romances imperiales siguen desaparecidos. Todo parece apuntar a que el último que los tuvo entre sus manos, según está documentado, fue Gallardo. No obstante, no es su ejemplar el único del que se ha perdido la pista, pues, desafortunadamente, los de los otros seis poseedores que hemos localizado en este trabajo se perdieron en algún momento del pasado, víctimas, como en el caso de Lastanosa, de la pésima gestión de sus bibliotecas tras la muerte de sus propietarios. Su biblioteca se dispersó por toda Europa inmediatamente después de su muerte, y ejemplares que le pertenecieron se encuentran en la actualidad en bibliotecas públicas y privadas alrededor del mundo. Tal vez en estas últimas es donde haya que prestar más atención por si algún coleccionista particular sacara a la luz en el futuro algún ejemplar de los Romances imperiales.

De hecho, los Romances imperiales aparecen en el Repertorio de impresos españoles perdidos e imaginarios, ${ }^{28}$ lo que quiere decir que para cuando se realizó dicho repertorio, así como en la actualidad, se le consideró una obra desaparecida, pero, como se observa de la importante aunque reducida nómina de poseedores, en absoluto imaginaria. Un aspecto que a día de hoy tampoco podemos resolver es el de si estos siete individuos tuvieron en su poder un ejemplar particular de los Romances imperiales o si, por el contrario, pudieron haber poseído el mismo en fechas distintas.

\section{La Historia Ymperial de Mexía, Los vivos retratos de todos los emperadores de Goltzius y los Romances imperiales de Sayago: ¿meras coincidencias?}

Un punto sobre el que creo interesante detenernos, a pesar de que la crítica ha pasado por alto este aspecto, es la posible relación que existió entre la Historia ymperial y cesárea de Pedro Mexía (Sevilla, Dominico de Robertis, 1547), Los vivos retratos de todos los emperadores de Hubert Goltzius (Amberes, Joss van Gietleughen, 1560) y nuestros Romances imperiales.

$\mathrm{El}$ primer indicio que nos sugiere esta vinculación es la evidente similitud que puede observarse al comparar los tres títulos completos: Historia Ymperial en la qual en summa se contienen las vidas y hechos de todos los emperadores de Roma, desde Iulio Cesar hasta el emperador Maximiliano, Los vivos retratos de todos los Emperadores, desde Julio César al Emperador Carlos $V$ y Romances imperiales de todos los Emperadores Romanos desde Julio César hasta el Emperador Maximiliano. Las tres obras versan, aparentemente, sobre los personajes y las hazañas de los Emperadores, no sólo romanos, sino también germánicos. El punto final de los textos de Mexía y Sayago es el relato de la vida de Maximiliano de

\footnotetext{
28 Universidad Complutense de MADrid. Departamento de Bibliografía, Repertorio de impresos españoles perdidos e imaginarios, 3 v. Madrid, Ministerio de Cultura, Dirección General de Bellas Artes, Archivos y Bibliotecas. Instituto Bibliográfico Hispánico, 1982, I, núm. 4233.
} 
Habsburgo, abuelo del Emperador Carlos V, de quien le proviene el título imperial. Es en el retrato de Carlos $\mathrm{V}$ y en el de su hermano Fernando (el Emperador Fernando I) donde concluyen Los vivos retratos. Bajo estas tres obras se encuentran hermanados el propósito de justificar la dignidad imperial del Rey de España y el de servir de libro para la educación, reflejo y entretenimiento de un Felipe II que, cuando en 1565 se imprimieron los Romances imperiales, contaba ya con cerca de cuarenta años.

La obra de Mexía vio la luz en la imprenta sevillana en 1547; en 1560 fueron impresos Los vivos retratos de Goltzius en Amberes; los poemas de Sayago hicieron lo propio en Sevilla el año 1565, lo que no nos aporta información acerca de cuándo se acabaron de escribir, ni de cuándo fueron concebidos. Fuera como fuese, los años que median entre las tres obras nos permiten suponer que, tras observar el éxito de la Historia Ymperial (cuya finalidad era la de presentarse ante Carlos V como óptimo candidato a cronista oficial), Sayago procurara imitar la obra tras una labor de versificación e inspirado, quizás, por los retratos del pintor flamenco. No obstante, cabe también la posibilidad de que los Romances imperiales fueran concebidos como una parodia del escrito de Mexía, si tomamos por cierto el estilo rústico que le imputa Nicolás Antonio. Precisamente, la Historia ymperial también fue objetivo de críticas hacia su estilo por parte de Capmany y de Montpalau:

«El estilo (...) es castizo, claro, grave y conciso; mas no siempre noble, igual, ni correcto (...). Lo que se llama elegancia, viveza y hermosura, apenas se hallarán en esta obra, y en pocas partes relucen aquella energía y nervio de que es capaz un compendio histórico. (...) Mezcla con la noble narración expresiones comunes, y más propias del estilo familiar que de la dignidad histórica». ${ }^{29}$

Como consecuencia de ello, los Romances imperiales pudieron haber tenido algún tipo de relación con las obras de Mexía y de Goltzius: pudieron haberse concebido como una versificación, en forma de cancionero antológico, de la vida de los emperadores, o como una parodia en verso utilizando un estilo rústico, pero que en ningún caso dependería de la competencia cultural de Pedro de Sayago. De lo que no cabe duda es de que estas tres obras, desde tres perspectivas muy distintas, forman parte de una literatura proimperial que coincide con un momento de entusiasmo nacional generalizado y de necesidad de legitimar el imperio que se ha construido en Europa desde la política matrimonial de los Reyes Católicos. Para ello, se vincula a las dos coronas de los Habsburgo (la española y la austríaca) con los Emperadores romanos y germánicos en una suerte de genealogía de la autoridad imperial en Europa.

\footnotetext{
${ }^{29}$ Antonio de CAPMANy y DE MONTPALAU. Tesoro de los prosadores españoles desde la formación del romance castellano hasta fines del siglo XVIII. Recopilado y ordenado por Eugenio de Ochoa. París, Baudry. Librería Europea, 1841, pág. 232.
}

Titivillus, ISSN 2387-0915, ISSN-e 2603-9966, 4 (2018), pp. 27-37 


\section{Conclusiones}

Una vez trazado en las páginas precedentes el recorrido por la información de que disponemos acerca de Pedro de Sayago, construido principalmente sobre datos que nos han llegado accidentalmente y sobre las hipótesis que hemos podido formular, llegamos a la conclusión de que estamos ante un poeta vinculado estrechamente a la casa ducal de Medina Sidonia. Sayago vivió con interés su momento histórico, marcado por el ideal imperial de los Austrias mayores. Dicho interés se observa con claridad en la Batalla de la Muerte, y con total seguridad la finalidad propagandística encontraría su expresión en los desaparecidos Romances imperiales. Del mismo modo que Mexía o Goltzius, Sayago debió de participar de esta moda imperial que retrocede hasta Julio César para justificar los orígenes de la autoridad de los Habsburgo sobre la Europa de mediados del siglo XVI.

El éxito de que gozaron los Romances imperiales queda atestiguado por el número y la relevancia de los poseedores que hasta aquí hemos podido documentar, a la espera de que posteriores inventarios permitan rastrear nuevos poseedores de cuyas bibliotecas sí conozcamos el devenir. Independientemente de las ediciones que se han supuesto, lo indudable es que los Romances imperiales se imprimieron en Sevilla, en casa de Alonso de Coca, el año 1565, que al menos un ejemplar cruzó el océano para llegar a América y que desde el siglo XIX se le ha perdido completamente la pista.

Resta aún un largo camino por andar hasta llegar a conocer (si es que alguna vez damos con los instrumentos para hacerlo) cómo fueron en realidad los Romances imperiales, qué pudo haber llevado a Sayago a componerlos y qué papel desempeñó dentro de los romanceros del XVI y dentro del conjunto de obras que recorren la historia imperial desde sus orígenes romanos hasta los antepasados más próximos de nuestros Austrias Mayores. Hasta que ese momento llegue, sólo podremos suponer, sugerir y trabajar sobre hipótesis o referencias indirectas: labor ardua, peligrosa cuando la imaginación supera el rigor y lógicamente insuficiente en tanto que inconcluyente. Hasta aquí llega por ahora lo que conocemos sobre esta peculiar obra de un poeta aparentemente tan peculiar como Pedro de Sayago. Conocimiento que confiamos poder ampliar en un futuro con datos basados en algún ejemplar que pueda aparecer de los Romances imperiales. 
